This item was submitted to Loughborough's Research Repository by the author.

Items in Figshare are protected by copyright, with all rights reserved, unless otherwise indicated.

\title{
Multiscale boundary frictional performance of diamond like carbon coatings
}

PLEASE CITE THE PUBLISHED VERSION

https://doi.org/10.1016/j.triboint.2018.12.039

PUBLISHER

(C) Elsevier BV

VERSION

AM (Accepted Manuscript)

PUBLISHER STATEMENT

This paper was accepted for publication in the journal Tribology International and the definitive published version is available at https://doi.org/10.1016/j.triboint.2018.12.039

\section{LICENCE}

CC BY-NC-ND 4.0

\section{REPOSITORY RECORD}

Humphrey, Ed, Nick Morris, Ramin Rahmani, and Homer Rahnejat. 2018. "Multiscale Boundary Frictional Performance of Diamond Like Carbon Coatings". Loughborough University. https://hdl.handle.net/2134/36541. 


\title{
Multiscale boundary frictional performance of Diamond Like Carbon coatings
}

\author{
E. Humphrey, N.J. Morris*, R. Rahmani and H. Rahnejat \\ Wolfson School of Mechanical, Electrical and Manufacturing Engineering, Loughborough \\ University, Loughborough, UK \\ Corresponding author: N.J.Morris@lboro.ac.uk
}

\begin{abstract}
This paper investigates the frictional performance of a PECVD hydrogenated undoped DLC coating and the alternative super-finished gear steel surface pairs. A tribometer replicates the conditions found in the conjunction of a performance racing transmission spur gear pair. In mixed and boundary regimes of lubrication the DLC contact is shown to have a lower coefficient of friction despite having comparable surface topography when measured using optical interferometry. To determine the mechanisms responsible for improved friction of DLC coated tribo-pairs atomic force microscopy is used. It is shown that the nanoscale surface topography of the investigated PECVD DLC coated pairs reduces the real asperity contact area formed at the same load carrying capacity. This highlights a contributing mechanism for improved friction with the DLC coating.
\end{abstract}

Keywords: DLC; Friction; Fractal surfaces; contact mechanics

\section{Nomenclature}

$\begin{array}{ll}A & \text { Asperity contact area } \\ A_{0} & \text { Apparent (Hertzian) contact area } \\ D & \text { Fractal dimension } \\ \text { E } & \text { Combined Young's modulus of elasticity } \\ E^{*} & \text { Effective Young's modulus of elasticity of the contact } \\ E_{1,2} & \text { Young's moduli of elasticity of contacting surfaces } \\ F_{N} & \text { Applied load } \\ f & \text { Total friction } \\ f_{b} & \text { Boundary friction } \\ f_{v} & \text { Viscous friction } \\ G & \text { An intermediate calculation parameter } \\ G_{e}{ }^{*} & \text { Non-dimensional material parameter } \\ G_{f} & \text { Fractal parameter } \\ H & \text { Hurts exponent } \\ h_{0} & \text { Central contact lubricant film thickness } \\ L & \text { Hertzian contact diameter } \\ m & \text { Gradient } \\ \bar{p} & \text { Asperity contact mean pressure } \\ R & \text { Reduced contact radius } \\ S & \text { Power spectrum } \\ U_{e} & \text { Lubricant entrainment velocity } \\ U_{e}{ }^{*} & \text { Non-dimensional speed (rolling-viscosity) parameter }\end{array}$


$W_{e}{ }^{*} \quad$ Non-dimensional load parameter

\section{Greek Symbols:}

$\alpha$

$\alpha_{0}$

$\eta_{0}$

$\tau_{0}$

$\tau_{b}$

$\zeta$

$\omega$

$\omega_{L}$

$\omega_{0}$

$\sigma$

$\sigma_{0}$

$\lambda$

$\lambda_{0}$

$\gamma$

$v$
An intermediate calculated term

Piezo-viscosity index

Atmospheric lubricant dynamic viscosity

Lubricant Eyring shear stress

Shear stress of adsorbed/bonded tribo-film

Pressure-coefficient of boundary shear strength

Frequency

Length scale frequency

Upper cut-off frequency

RMS roughness

Mean Stress

System wavelength scale

Upper cut-off length scale

Magnification factor

Poisson's ratio for the tribo-pair materials

\section{Abbreviations}

$\begin{array}{ll}\text { AFM } & \text { Atomic Force Microscopy } \\ \text { DLC } & \text { Diamond-Like Carbon } \\ \text { EDS } & \text { Energy Dispersive Spectroscopy } \\ \text { EHL } & \text { Elastohydrodynamic Lubrication } \\ \text { LFM } & \text { Lateral Force Mode } \\ \text { CVD } & \text { Chemical Vapour Deposition } \\ \text { RMS } & \text { Root Mean Square deviation } \\ \text { SEM } & \text { Scanning Electron Microscope } \\ \text { XPS } & \text { X-ray Photoelectron Spectroscopy }\end{array}$

\section{Introduction}

Improved fuel efficiency in the automotive industry has been a key objective, which also reduces the harmful emissions with adverse environmental impacts [1]. Powertrain downsizing has resulted from these requirements. However, there has also been a customer demand for maintaining or even improving upon the output power. Therefore, the concept of high output power-to-light (and durable) weight ratio has become commonplace [2]. The same requirements have been extended to the drivetrain system. Significant effort has been expended in improving drivetrain efficiency as well as its durability. In the case of the latter, thin wear-resistant hard coatings are progressively used to withstand the ever rising contact loads as the result of increasing output power. Diamond-Like Carbon (DLC) coating is now 
more commonly employed in the automotive industry, particularly in high performance powertrains to reduce wear and friction within contacts operating under severe conditions [3, 4].

Some recent advances in technology have led to harsher tribological operating conditions, such as extreme shear rates, generated high contact pressures and temperatures. Therefore, increased demands have been put on lubricant performance, as well as lubricant-surface interactions, in particular with coated surfaces such as DLC $[5,6]$. DLC coatings are widely employed for components that operate under boundary or mixed regimes of lubrication as they can mitigate undesired tribological problems such as fatigue spalling [7], wear and friction [8, 9]. The mechanical properties of DLC coatings depend on a number of parameters, such as the method of deposition, hydrogen content, presence of doping elements, the bond ratio of $\mathrm{sp}^{2}: \mathrm{sp}^{3}$ and the thickness of the coated film. Surface coating design can also significantly influence the mechanical and tribological properties. The designs may include multi-layer structures and multi-component compositions to improve specific system properties in mitigating certain undesired effects such as wear and fatigue [7, 10].

DLC coatings are a form of amorphous carbon $(\mathrm{a}-\mathrm{C})$ or hydrogenated amorphous carbon $(\mathrm{a}-\mathrm{C}: \mathrm{H})$ with an atomic structure comprising $\mathrm{sp}^{3}$ and $\mathrm{sp}^{2}$ hybridisations. Coating properties vary significantly with the $\mathrm{sp}^{2}: \mathrm{sp}^{3}$ bond ratio and the hydrogen content $[11,12]$. Other varieties of DLC coatings may be devised through doping its chemical structure with elements such as Titanium, Tungsten, Molybdenum or non-metals such as Silicon, Nitrogen or Fluorine [13]. DLC coatings may be fabricated using Physical Vapour Deposition (PVD) techniques such as sputtering, arc evaporation or Plasma-Enhanced Chemical Vapour Deposition (PECVD). The adhesion of the DLC coating to the substrate is often improved through use of Chromium or Tungsten carbide interlayers. It should be noted that a form of DLC coating failure is through exfoliation at the interface with the substrate material caused by increasing rates of shear [7]. The wide variety of available DLC coatings allow for application-specific designs to achieve the desired performance. In conjunction with lubricant additive pack interactions within the system, an optimised lubricant additive package would allow for durable low friction, low wear operation. This leads to the lubricant-surface system approach in modern tribological perspective $[14,15]$, an approach also undertaken in the current paper.

There have been many recent investigations of the effect of lubricant additives on DLC coating; topology and frictional performance. Reduction of boundary and mixed friction occurs due to the presence of organo-Molybdenum-based friction modifiers such as MoDDC, interacting with the DLC coated surfaces, which have been widely reported [16-18]. However, this combination has also been shown to cause high wear rates [19-21]. The mechanism responsible for the high wear rate of DLC, when lubricated with Organo-molybdenum-based friction modifiers is still somewhat unclear. Research results suggest that addition of ZDDP to the lubricant additive package could mitigate against this phenomenon [20]. One suggested mechanism is the hybridisation of the atomic structure from $\mathrm{sp}^{3}$ to $\mathrm{sp}^{2}$ bonds due to high generated pressures, shear and temperatures [21].

Some reported works have focused on the consequential actions of some lubricant additives on DLC coatings under boundary and mixed regimes of lubrication [22-25] and even fewer under severe operating conditions [26]. They also record any improvements in frictional performance in boundary regime of lubrication $[22,24]$. However, no definitive mechanism for improved boundary friction is surmised, with most explanations focusing on surface-additive interactions and formation of tribo-films. Frequently, the studies have focused on DLC-on-Steel contacts which can cause difficulties when intending to determine the influence of lubricant additives on the frictional performance of the contact. However, it has been shown that DLC coatings on one or both of the contacting surfaces mitigate initial high friction, commonly experienced during the running-in wear phase in comparison to Steel-on-Steel contacts [24]. Vengudusamy et al [22] showed significant reduction in friction for the initial stages of a-C:H:WC, a-C:H:W and a-C:H tribo-pairs in comparison to Steel-on-Steel contacts with an MoDTC friction modifier additive. Podgornik et al [23] demonstrated an improvement for W-DLC surface pairs over steel pairs. The authors attributed this to a developed DLC transfer film as the primary mechanism for improved frictional performance. For cam-follower conjunctions, Kano [27] showed that when DLC surfaces are introduced a reduction in friction can be obtained in comparison to Steel-on-Steel conjunctions. 
Tasdemir et al [28] employed a pin-on-disc tribometer to investigate a range of DLC, Steel and lubricant combinations, ascertaining their frictional performance. The results demonstrated that the DLC pairs and DLC-on-Steel contacts reduced friction in comparison with the Steel contacting pairs with most of the lubricant types used.

The current paper presents a study of DLC-on-DLC and Steel-on-Steel tribo-pairs, lubricated by a fully formulated high performance transmission fluid used for motor racing applications. The use of a precise testing methodology provides detailed information on the complexity of lubricated DLC conjunction and the influence of parasitic boundary losses within high performance transmissions. The improvements in frictional performance, attained through introduction of DLC coatings are explained through an analytical contact mechanics model.

\section{Experimental methodology}

\subsection{Overview}

A combined analytical-experimental approach is used. A series of measurements are undertaken to characterise the surface topography and allow the evaluation of real contact area using an analytical model described in section 5. The system frictional performance is evaluated through representative microscale experiments. Surface topographies of Steel as well as DLC coated samples are measured across physics of scale from micro to nanoscales using white light interferometry and Atomic Force Microscopy (AFM).

\subsection{Tribometry}

A precision in-house manufactured uni-directional pin-on-disc tribometer (Figure 1) replicates some aspects of high performance transmission gear meshing contacts through representative contact conditions [29]. The applied normal load on the disc sample through the pin is generated by a dual cantilever loading mechanism, resulting in a circular point contact. The rotation of the sample disc causes relative motion between the two contacting surfaces, generating friction which is measured. An enclosed heating system raises and maintains the bulk surface temperature of the disc samples. A Ktype thermocouple feedback loop is used to maintain/regulate the surface temperature of the samples. A syringe driver supplies a fixed rate of lubricant feed onto the sample surface with the height of the inlet meniscus controlled by a roller wiper system [29]. Therefore, repeatable conditions are assured for all the reported experiments.

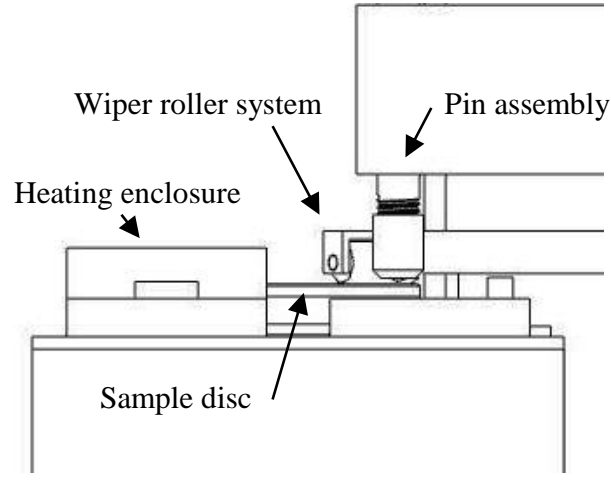

(a)

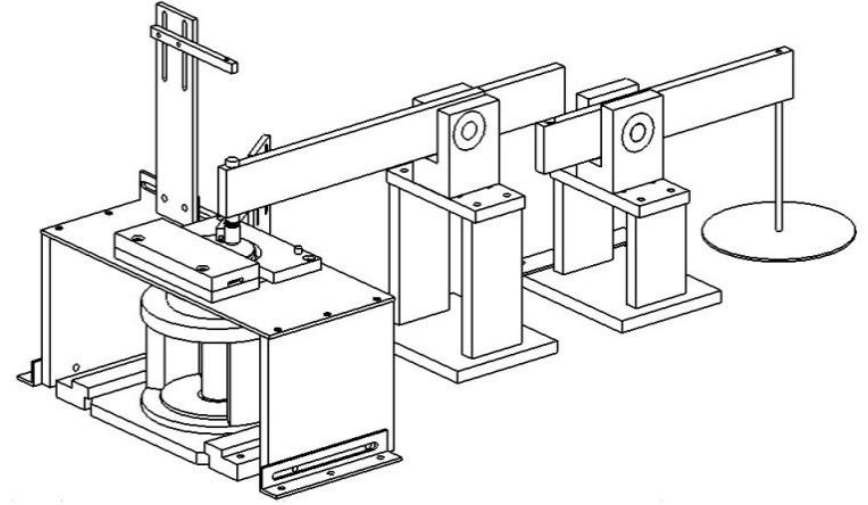

(b)

Figure 1: Schematic representation of the in-house precision uni-directional pin-on-disc tribometer; (a) detailed view of the pin contact with sample discs with wiper roller system enclosed within the heating system, (b) an overview of the tribometer

The tribo-pairs investigated are DLC-on-DLC and Steel-on-Steel pairs, lubricated by a fully formulated high performance transmission fluid with a kinematic viscosity of $6.9 \mathrm{cSt}$ at $100{ }^{\circ} \mathrm{C}$. The interface at the pin-disc conjunction is subject to pure sliding, in comparison to the involute gear pairs which are subject to slide-roll ratios within the meshing cycle. The tribometer is used to measure the microscale 
friction, as well as to activate the lubricant's boundary active additives. Typical operating conditions for high performance transmissions are replicated [30,31] using two methods to characterise the tribometer and transmission tribological contacts. Humphrey et al [29] showed that the dimensionless viscous and elastic parameters in the Greenwood chart [32] are: $G_{v}=10^{7}-10^{13}$ and $G_{e}=10^{5}-$ $10^{11}$ for a high performance transmission and $G_{e}=10^{8}-10^{9}$ and $G_{v}=10^{9}-10^{10}$ for the pin-ondisc tribometric studies. This shows that both contact conditions reside within the piezo-viscous elastic (elastohydrodynamic) regime of lubrication. The Deborah number [33] was also calculated by Humphrey et al [29] to ascertain the prevailing tractive regime that the lubricant is subjected to in the transmission gearing, as well as the replicated conditions in the pin-on-disc tribometry. It was shown that the Deborah number (a measure of lubricant viscoelastic response) was greater than unity, indicating non-Newtonian traction [9]. It is, therefore, reasonable to use the pin-on-disc experiments as quite representative of the observed conditions in parts of high performance racing transmission gear meshing cycles.

\section{Material characterisation}

The DLC coating considered in the current investigation is an undoped, amorphous, hydrogenated coating (a-C:H), obtained commercially from an industrial supplier. The coating was deposited using plasma enhanced chemical vapour deposition method (PECVD). The DLC coating is deposited onto the hardened gear Steel disc substrates and grade 10 AISI52100 ball bearing Steel is used as the counter face pin. A Chromium adhesion layer (Figure 3) is used to improve the interfacial layer adhesion of the DLC coating with the substrate Steel surface. The Manganese detected within the DLC coating is commonly used to improve the running-in performance of the coating [34]. The thickness of the DLC coating is measured using a focused ion beam Scanning Electron Microscope (SEM). A $20 \mu \mathrm{m}$ trench (Figure 2) is bored in 3 locations to determine the average coating thickness. The DLC coating thickness for the discs was $1.7 \pm 0.05 \mu \mathrm{m}$. To measure the coating thickness on the pin, the sphere was mounted in Bakelite, ground to the circumference and the coating thickness was measured using SEM. The measurement results show that the coating thickness for the pin is $1.2 \pm 0.1 \mu \mathrm{m}$. The micro-hardness of the two sample surfaces was measured using an automated micro hardness tester (Vickers indenter). Ten locations on the samples' surfaces were measured. The steel sample exhibited $749 \mathrm{HV}$ for a $10 \mathrm{~kg}$ applied load and the DLC coating exhibited $856 \mathrm{HV}$ for a $0.1 \mathrm{~kg}$ applied load.
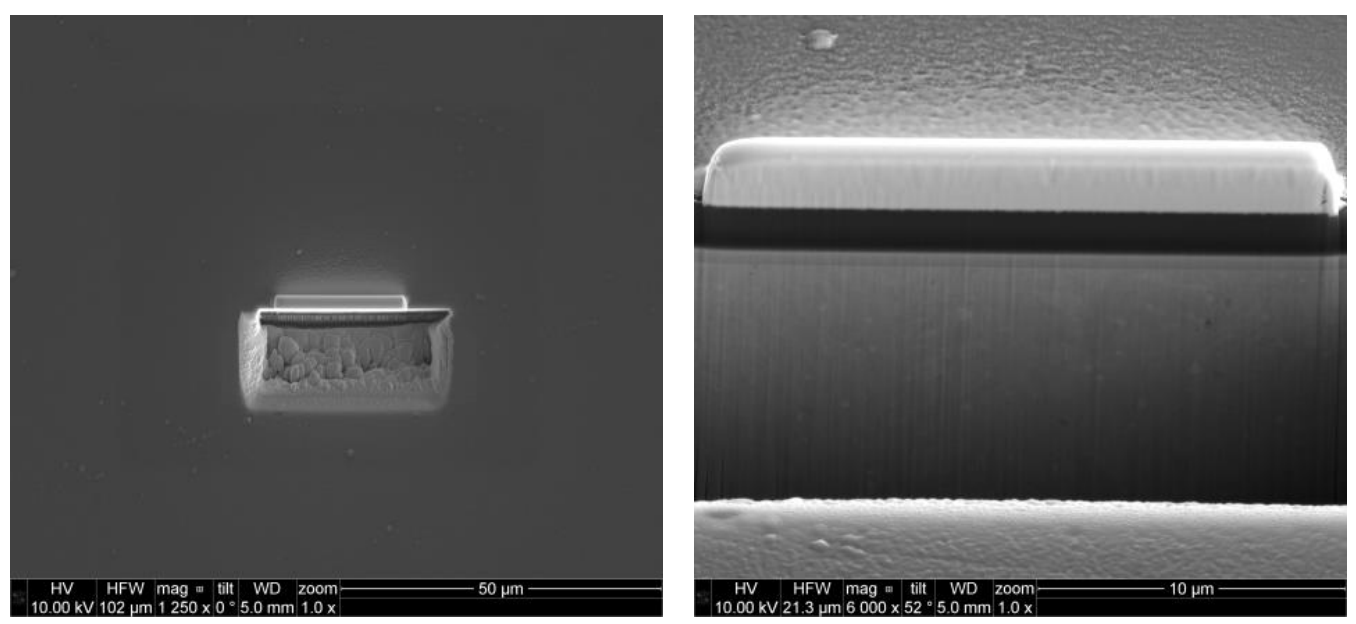

Figure 2: Focused ion beam SEM images of the DLC coating (left) Top view of the trench milled with the FIB, (right) of the cross-sectional view of the trench to determine the coating thickness 


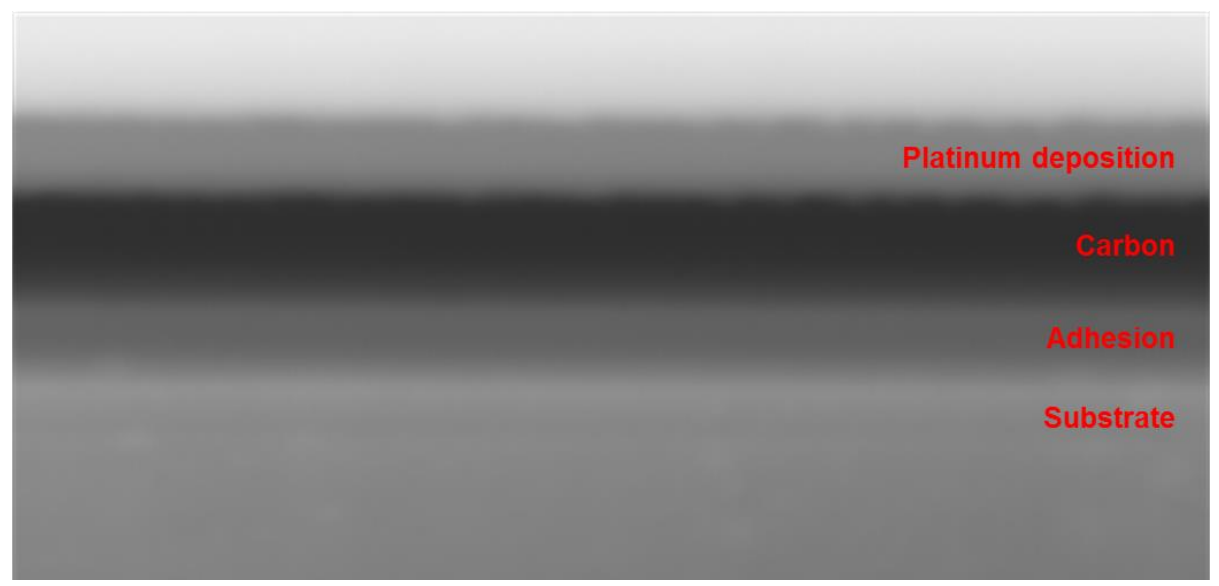

3(a)

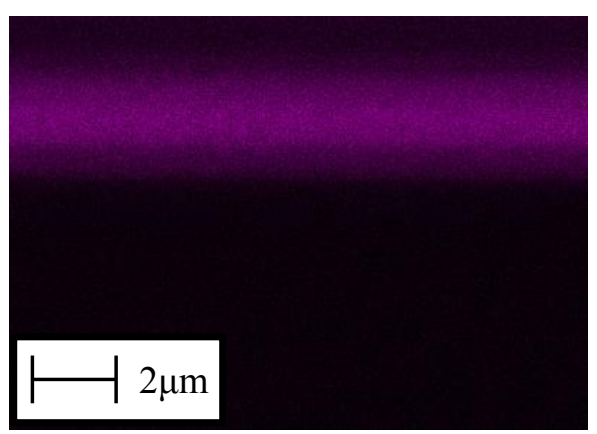

3(b)

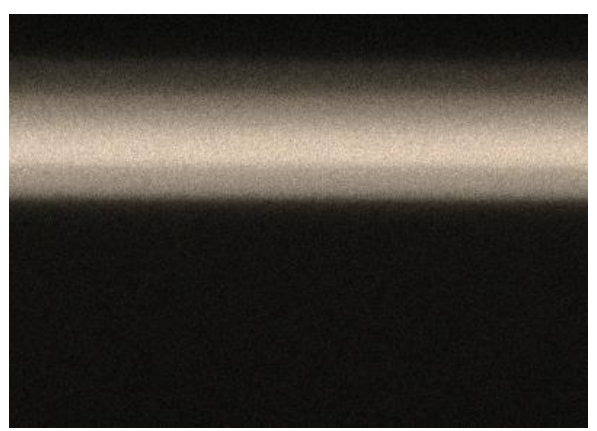

$3(d)$

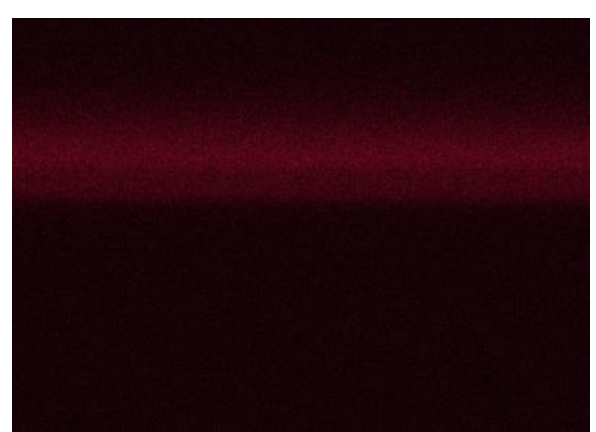

$3(\mathrm{c})$

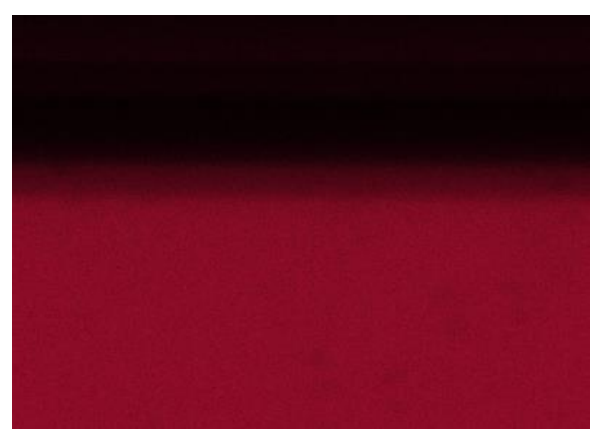

$3(\mathrm{e})$

Figure 3: EDS intensity maps of the DLC coating; 3(a) Field of view (individual layers of the DLC coating have been labelled in red), 3(b) Carbon, 3(c) Manganese 3(d) Chromium and 3(e) Iron

An Argon-assisted sputtering PECVD technique is used to deposit the coating. The Carbon composition and the content of the DLC coating is analysed using XPS and EDS. Figure 4 shows the ratio of $\mathrm{Sp}^{3}$ to $\mathrm{Sp}^{2}$ carbon bonds. The ratio of $\mathrm{Sp}^{2} / \mathrm{Sp}^{3}$ (Graphite structure/ Diamond structure) bonds within the DLC coating affects coating mechanical properties. For example a coating with high $\mathrm{Sp}^{3}$ carbon bond fraction will promote high hardness, whereas a high $\mathrm{Sp}^{2}$ carbon bond fraction will promote reduced friction. The XPS results show that the DLC coating has a $\mathrm{Sp}^{2} / \mathrm{Sp}^{3}$ ratio of $\sim 50 \%$ determined from the area comparison of the $\mathrm{Sp}^{3}$ and $\mathrm{Sp}^{2}$ peaks. This is in line with other published $\mathrm{Sp} 2 / \mathrm{Sp}^{3}$ ratios for DLC coatings [35]. The curve-fitting process for the individual contributions considers the shape of the peaks to be $30 \%$ Lorentzian/ $70 \%$ Gaussian. The $\mathrm{Sp}^{3}$, Carbon single bond and carbon double bond have symmetric peaks, in comparison to the $\mathrm{Sp}^{2}$ peak which is asymmetric. The determined peak binding energy of the $\mathrm{Sp}^{2}$ and $\mathrm{Sp}^{3}$ peaks are $284.02 \mathrm{eV}$ and $284.9 \mathrm{eV}$, respectively. The carbon single bond peak energy is $286.45 \mathrm{eV}$ and the carbon double bond peak energy is 288.38 . A good correlation of the fitted 
curve with the experimental peak, shown in figure 4, imparts good confidence in the DLC carbon composition.

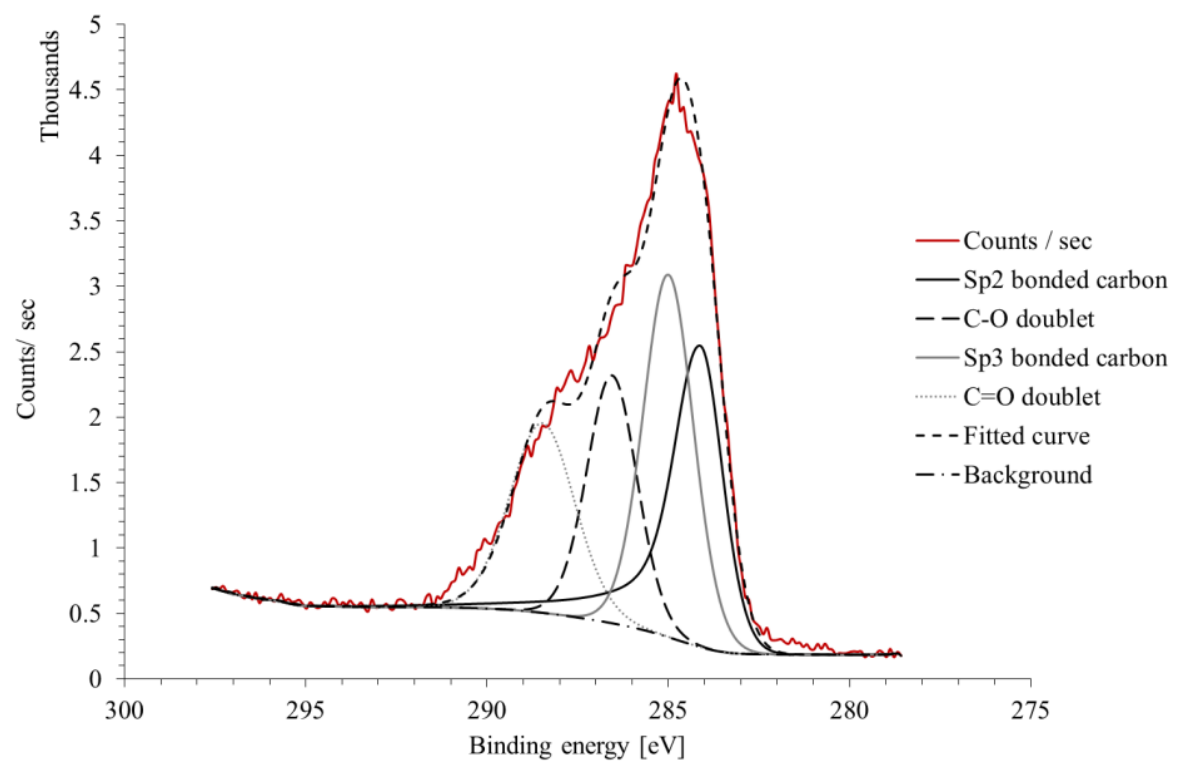

Figure 4: XPS high resolution scan of the DLC coating

The Steel-on-Steel pair comprises a hardened gear Steel and AISI52100 grade 10 ball bearing Steel as hemispherical pins. SEM images of the studied sample surfaces prior to testing are shown in Figure 5. The Steel sample shows a highly finished isotropic topography with micro-pits in comparison with the DLC coating which has an intricate structure formed of nanoclusters.
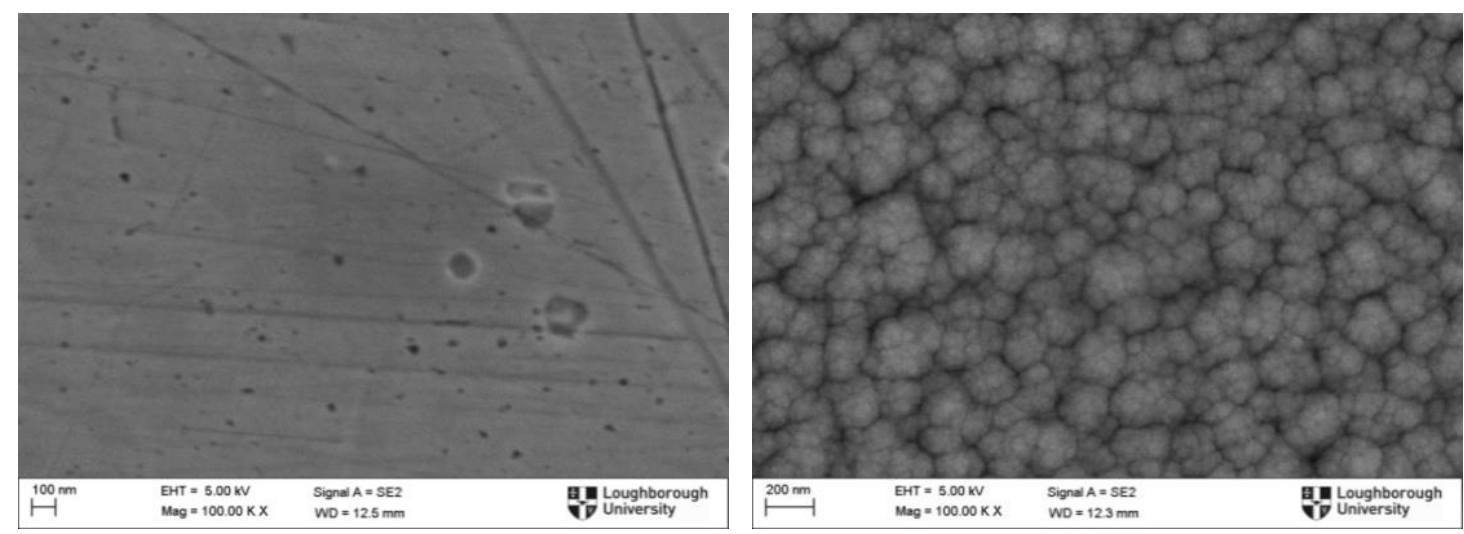

Figure 5: SEM images of the Steel (left) and DLC coated (right) virgin surface topography

\subsection{Surface characterisation}

The microscale surface topographies of the two sample types are observed to have similar RMS values, although a significant roughness height difference is observed when measured with the white light interferometer; Zygo. These are shown in Figure 6. However, the high resolution and magnification of the SEM images (Figure 5) indicate that there is a significant difference in their nanoscale surface topographies, not reflected by the WLI determined RMS values. To ensure that the appropriate length scales of the surface roughness is considered in the contact mechanics model, surface roughness measurements are performed with different measurement techniques which impose varying upper and lower frequency cut-offs. 

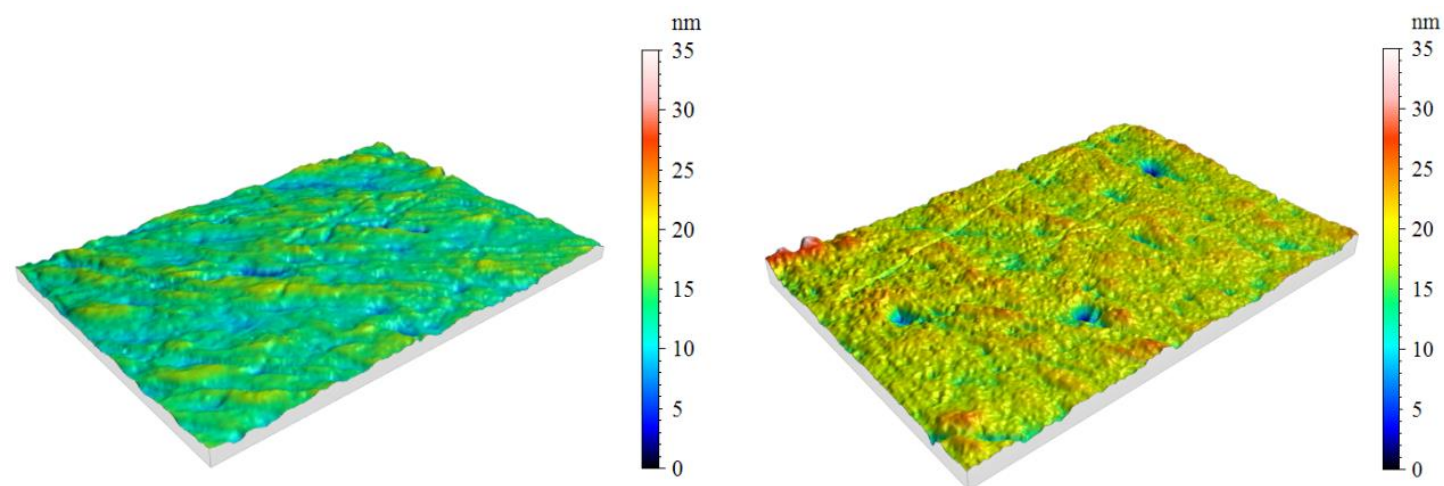

Figure 6: $200 \mu \mathrm{m} \times 284 \mu \mathrm{m}$ area of Steel sample (Left) and DLC coated sample (Right) using non-contact optical white light interferometry
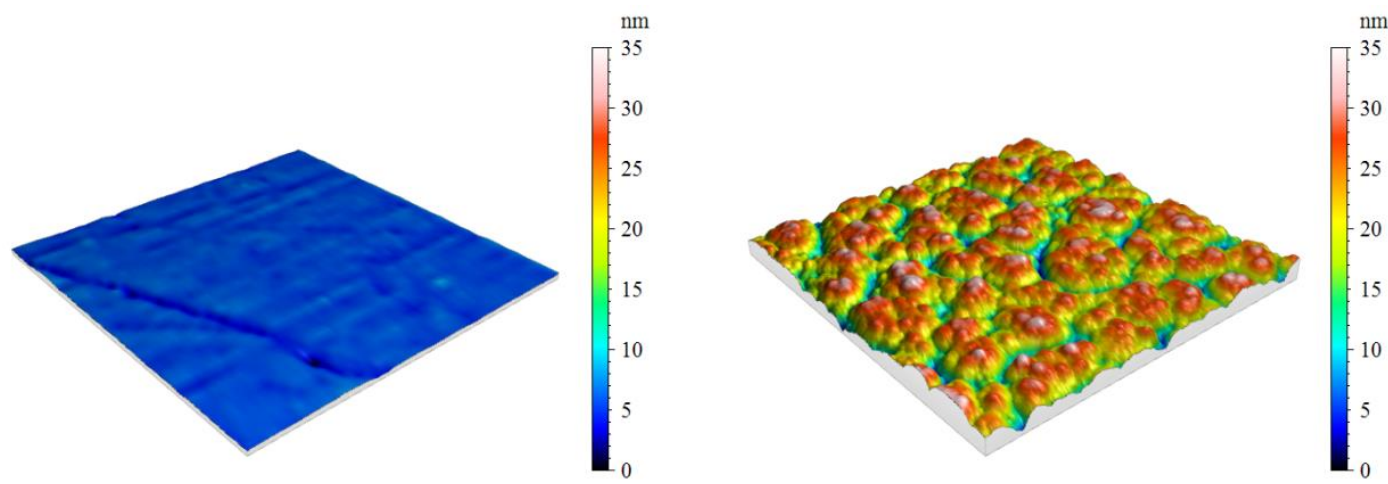

Figure 7: $1 \mu \mathrm{m}^{2}$ area of steel (left) and DLC coated sample (right) using AFM

Figure 6 and 7 show images of the sample surfaces measured using varying techniques (as indicated), for sample resolution and scale. The surface topographic variations with measurement scale can be seen to have an increasing level of detail, indicating self-affinity. A significant observation is that the lateral resolution, as well as the vertical sensitivity of the measurement equipment is important in determining the roughness of the DLC surface. Measurements taken using the white light interferometer indicate similar values of the RMS height deviation of $2.65 \mathrm{~nm}$ and $2.91 \mathrm{~nm}$ for the Steel and DLC samples, respectively. This is demonstrated in Figure 6. The white light interferometer used to measure this data has a lateral resolution of $0.64 \mu \mathrm{m}$ in comparison to Figure 7 which shows the measurements made by an AFM with a lateral resolution of $\sim 1 \mathrm{~nm}$. This improvement in lateral resolution provides a much greater level of detail and uncovers the nanoscale features of the investigated DLC surface, also shown through SEM images in Figure 5. There are significant differences in the nanoscale topography between the steel and DLC coated samples, hence the surfaces should be characterised through fractal analysis. A summary of material properties is listed in table 1.

Table 1: Material properties and surface topographical measurements of sample tribo-pairs

\begin{tabular}{ccccccccc}
\hline Material & $\begin{array}{c}\text { Description of } \\
\text { coating }\end{array}$ & $\begin{array}{c}\text { Adhesion } \\
\text { layer }\end{array}$ & $\begin{array}{c}\text { RMS } \\
(\mathrm{WLI}) \\
{[\mathrm{nm}]}\end{array}$ & $\begin{array}{c}\text { RMS } \\
(\mathrm{AFM}) \\
{[\mathrm{nm}]}\end{array}$ & $\begin{array}{c}\text { Fractal } \\
\text { dimension }\end{array}$ & $\begin{array}{c}\text { Fractal } \\
\text { parameter } \\
{[\mathrm{m}]}\end{array}$ & $\begin{array}{c}\text { Elastic } \\
\text { modulus } \\
{[\mathrm{GPa}]}\end{array}$ & $\begin{array}{c}\text { Coating } \\
\text { thickness } \\
{[\mu \mathrm{m}]}\end{array}$ \\
\hline Steel & Case hardened & - & 2.65 & 4.3 & 1.49 & $10^{-12}$ & 212 & - \\
$\begin{array}{c}\text { a-C:H } \\
\text { coated } \\
\text { steel }\end{array}$ & $\begin{array}{c}\text { DLC with } \\
\text { interface } \\
\text { adhesion layer }\end{array}$ & Chromium & 2.91 & 13.9 & 1.52 & $10^{-13}$ & 210 & 1.7 \\
\hline
\end{tabular}




\section{Experimental results}

Experimental and analytical modelling techniques are employed to determine the effect of multiscale frictional performance of DLC-on-DLC in comparison to Steel-on-Steel contact conditions.

\subsection{Tribometric results}

Frictional performances of the DLC and Steel surface pairs are established using a pin-on-disc tribometer (Figure 1). A circular point contact is formed by a hemispherical pin (radius $2.5 \mathrm{~mm}$ ) loaded onto a rotating sample disc. Tribometric tests are conducted with a nominal normal contact load for a given contact pressure with varying sliding velocities. This section presents the experimental test conditions, comprising a bulk material temperature of $100^{\circ} \mathrm{C}$, applied normal force of $20 \mathrm{~N}$, creating an equivalent Hertzian contact pressure of $2 \mathrm{GPa}$ with varying sliding velocities in the range $0.9-5.3 \mathrm{~m} / \mathrm{s}$. These are quite representative of meshing gear teeth pairs of high performance racing transmissions, as indicated in section 2.2. A fully formulated high performance transmission fluid is used for both tribopair types. The lubricant is from the same batch for all tests, thus avoiding any batch-to-batch variations through manufacturing inconsistences.

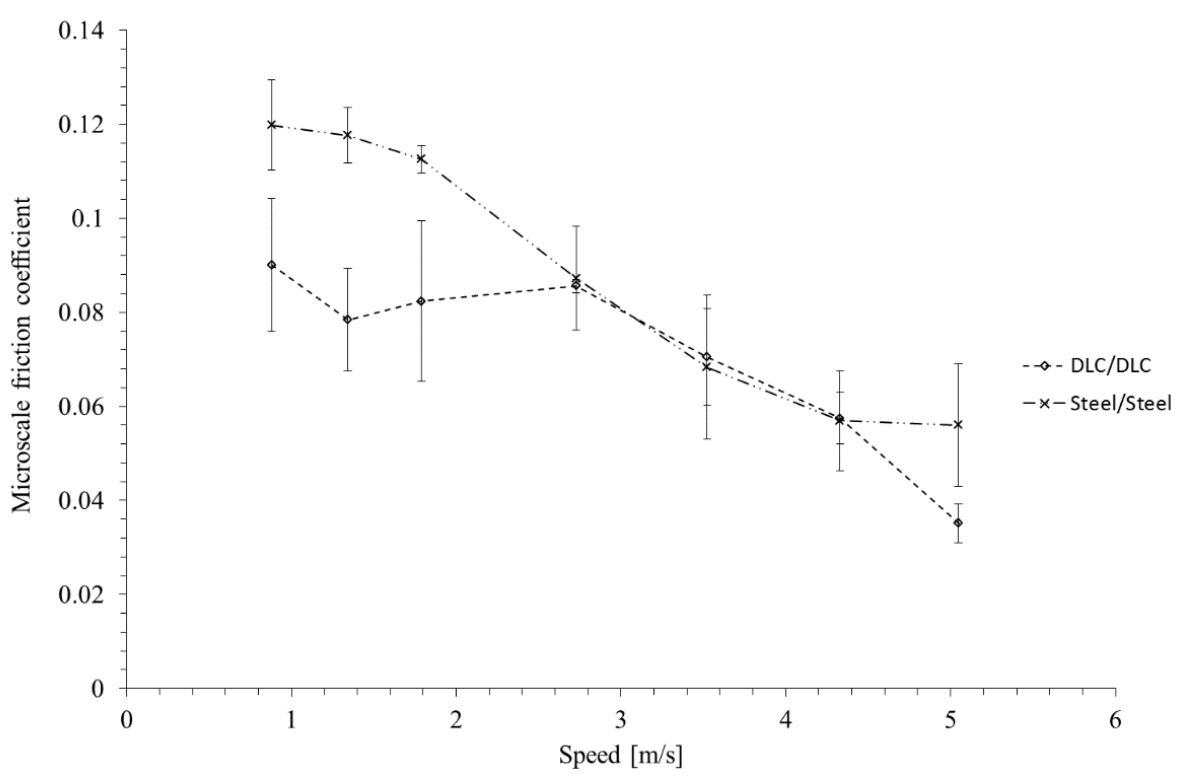

Figure 8: Measured microscale coefficient of friction variation with sliding velocity with lubricant-surface combinations

Figure 8 shows the microscale coefficient of friction variation with increasing sliding velocity. The contact conditions lead to mixed elastohydrodynamic regime of lubrication. The contact load is, therefore, carried by the formed thin lubricant film and the counter face contacting asperity pairs. As the sliding velocity is increased, there is greater interfacial separation on the account of a rising rate of lubricant entrainment into the contact. The fluid film elastohydrodynamic regime of lubrication tends to dominate with an increased film thickness. Consequently, the effect of asperity interactions and hence boundary friction contribution is reduced. Therefore, the role of any formed tribo-film is diminished with increasing speed of lubricant entrainment and a sufficient supply of lubricant at the inlet meniscus. This is clear by the convergence of the results for both cases at higher speeds, as shown in Figure 8 . Furthermore, the figure shows that the DLC-on-DLC contact has better frictional performance benefits at lower sliding velocities. This is because there is reduced lubricant film thickness, thus a greater contribution by mixed regime of lubrication. Any formed tribo-film also affects friction through the LFM measured boundary shear strength of asperities, $\zeta$. Thus, the formation, growth or wear of any tribo-film contributes to boundary friction. The following section investigates contributing mechanisms for this observation using analytical modelling techniques. 


\section{$5 \quad$ Analytical model}

An analytical model is required to investigate the underlying mechanisms responsible for the reduction of friction for the DLC samples under severe operating conditions; in mixed and boundary regimes of lubrication in comparison with the Steel surfaces. For this investigation the effect of the tribofilm has been neglected.

To validate the experimental trends observed within the tribometric tests, the film thickness under these instantaneous contact conditions is determined analytically by the regressed extrapolated lubricant film thickness equation of Chittenden et al [36] for point contact footprints. This extrapolated film thickness equation was obtained through regression analysis:

$h_{0}=R\left[4.31\left(U_{e}^{*}\right)^{0.68}\left(W_{e}^{*}\right)^{-0.073}\left(G_{e}^{*}\right)^{0.49}\left\{1-e^{\left[-1.23(\mathrm{R})^{0.67}\right.}\right\}\right]$

where, the non-dimensional groups are defined as:

$U_{e}{ }^{*}=\frac{\eta_{0} U_{e}}{E^{*} R}, W_{e}{ }^{*}=\frac{F_{N}}{E^{*} R^{2}}, G_{e}{ }^{*}=E^{*} \alpha_{0}$

and:

$\frac{1}{E^{*}}=\frac{\left(1-v^{2}\right)}{E}=\frac{\left(1-v_{1}^{2}\right)}{E_{1}}+\frac{\left(1-v_{2}^{2}\right)}{E_{2}}$

The lubricant rheological data is obtained commercially, with values of lubricant viscosity and pressure viscosity coefficient being $6.56 \mathrm{mPa}$.s at $100^{\circ} \mathrm{C}$ and $1.69 \times 10^{-8} \mathrm{~Pa}^{-1}$ respectively. The mechanical properties for the steel were taken from literature [29] and the DLC mechanical properties were provided by the commercial supplier and also taken from literature [37]. A summary of the material properties used is provided in table 2 .

Table 2: A summary of the mechanical properties

\begin{tabular}{cccc}
\hline Material & Property & Value & Unit \\
\hline \multirow{2}{*}{ DLC } & $E$ & 210 & $G P a$ \\
& $v$ & 0.22 & - \\
Steel & $E$ & 210 & $G P a$ \\
& $v$ & 0.3 & - \\
\hline
\end{tabular}

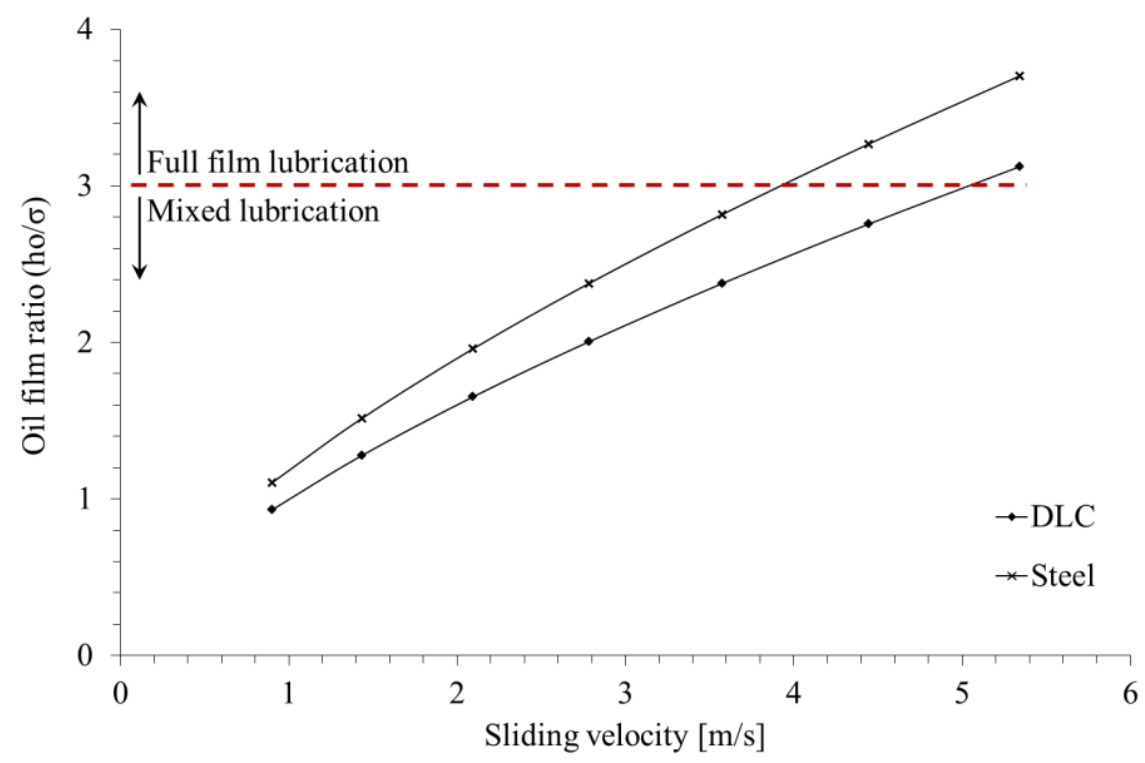

Figure 9: The oil film ratio for DLC coated and Steel samples under varying sliding velocities 
Figure 9 shows, the variation of the oil film thickness ratio with an increasing sliding velocity for the cases considered. A thicker elastohydrodynamic film is formed due to increased lubricant entrainment, reducing the direct interaction of the contiguous surfaces with increasing sliding velocity. This increase in lubricant film thickness enhances the oil film thickness ratio through the regimes of lubrication as shown. Figure 9 suggests that the considered contact remains mostly in the mixed elastrohydrodynamic regime of lubrication. This trend is in agreement with the experimental measurements (figure 8) as the coefficient of friction is higher at slower sliding speeds due to the higher contribution of boundary friction interactions. As the sliding velocity increases, the DLC and Steel surfaces produce similar values for the coefficient of friction (figure 8 ). This can be explained by the results in figure 9 , showing that the contacting surfaces tend to reach the higher end of the mixed regime of lubrication, where the full fluid film lubrication $\left(h_{0} / \sigma>3\right)$ effect gradually becomes dominant. The steel-pairs' contact at the highest examined speed has transitioned into the full fluid film regime of lubrication in comparison to the DLC pair. This transition is also observed in figure 8. In the case of DLC, figure 9 shows that the contact remains in the mixed regime of lubrication and only just makes the transition into full film lubrication for the highest sliding velocity. This is also evident in figure 8 by the reduction in the coefficient of friction.

Clearly, the difference between the two surface pair types occurs when mixed and boundary regimes of lubrication prevail. Therefore, the following section investigates the contact mechanics of the rough surfaces to explain the difference in their performance. For the sake of further clarity the influence of fluid film in surface separation is ignored as the lubricant is the same in all cases. The authors acknowledge that at the low sliding speeds the effect of surface topography and any adsorbed layers/tribo-film can become more pronounced and contribute to further improvement to friction within the contact.

In the current study a scale-independent fractal representation of the rough surface topography is presented. The surfaces are characterised by their fractal dimension, which is a surface-specific and scale-invariant parameter. Such a representation enables prediction of surface phenomena across multiple scales, formed from limited surface topographical observations [38, 39]

Classical Hertzian contact theory is used to predict the contact footprint semi-half width and the apparent contact area $[9,40]$. An assumption of the classical Hertzian theory is that the contacting surfaces are perfectly smooth, thus frictionless. However, this is not the case for real engineering surfaces. The interactions between rough contiguous surfaces have a significant impact on contact mechanics, including elasto-plasticity, adhesion and ultimately tribological performance [41-44]. It has been shown that self-affine surfaces' real contact area can be described by surface-specific fractal geometry $[38,45]$.

Engineering surfaces have surface roughness across multiple scales and are often of non-Gaussian topography, where progressive interaction levels take place [46], at each of which frictional characteristics alter. Therefore, an understanding of the nature of multi-scale topography is crucial in determining the tribological behaviour [47]. The real area of contact within a conjunction is critical as this has implications on system properties such as friction and heat transfer. A theory developed for randomly rough self-affine surfaces proposed by Persson [47-50] can be applied to both elastic and plastic deformations within a contact area.

The fractal nature of many engineering surfaces has been demonstrated by Majumdar and Bhushan [51]. This observation leads to the possibility that a specific surface can be described by its fractal dimension and parameters found from the power spectra of the Weierstrass-Mandelbrot (W-M) function. The average power spectrum follows the power law of the form:

$$
S(\omega)=\frac{G_{f}^{2(D-2)}}{\omega^{5-2 D}}
$$

Therefore, the average power spectrum is a function of frequency, which can be considered as the reciprocal of the wavelength of surface roughness. If the average power spectrum is plotted as a function of the frequency on a logarithmic scale, then the power law behaviour results in a linear region. For a linear region, which extends across multiple length scales, it is possible to describe the surface through fractal representation. The gradient of the plot can be used to determine the fractal dimension, $D$, as: 


$$
D=\frac{5-m}{2}
$$

Power spectral analysis is completed across the sample scanned sizes. Equation (4) suggests that the fractal dimension characterisation of a surface must comply with: $1<D<2$. When: $D=1$, the implication is that at the length scale considered, the surface is ideally smooth. A fractal dimension less than unity can be interpreted as negligible roughness contribution to the contacting area at the stated length scale. The power spectral density determines the mean spectrum calculated in all directions from an individual spectrum. In the current study 180 angular spectra are used to calculate the average power spectrum. Figure 10 shows the mean power spectra of the measured samples for the two surface-pair types using AFM and white light interferometric techniques for varying length scales. It can be seen that the Steel and DLC samples show similar gradient with lateral shifts for higher resolution scanning techniques (i.e. AFM). This confirms the self-affinity of the investigated surfaces. For the largest scan $\left(284 \times 213 \mu \mathrm{m}^{2}\right)$ and mid-scan $\left(20 \times 5 \mu \mathrm{m}^{2}\right)$ sizes for the DLC sample the gradients provide a fractal dimension: $D<1$, indicating that at these length scales the surface roughness may be considered as negligible. This is due to the insufficient lateral resolution required to define the nanocluster structure of the DLC. Therefore, the fractal dimension for the DLC samples is determined using AFM with the scan area of $1 \times 1 \mu \mathrm{m}^{2}$. Multiple measured sampled areas result in a fractal dimension in range of 1.49 -1.54 and the average gives a fractal dimension for the DLC coated sample of 1.52. The Steel sample fractal dimension is determined using the average fractal dimension for all the scanned length scales with all the employed measurement techniques, resulting in a range of $1.43-1.51$ and an average value of 1.49. All calculations carried out here use these average values.

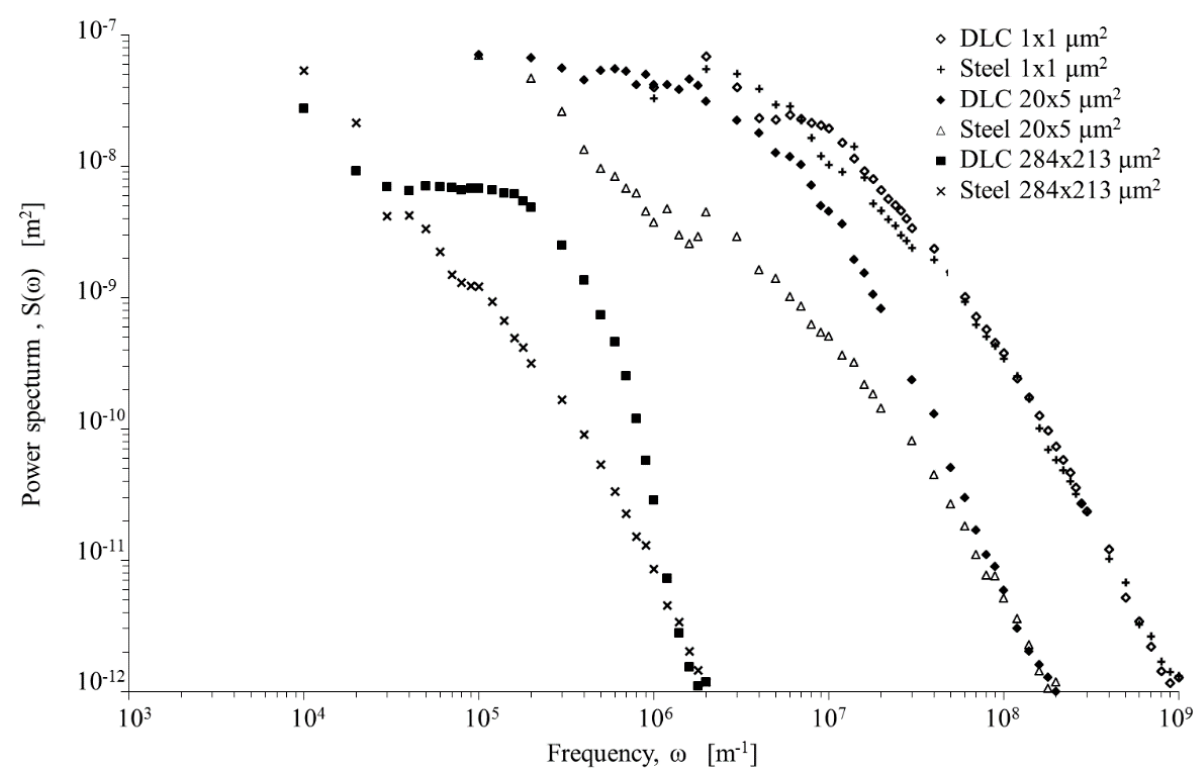

Figure 10: Average power spectrum of Steel and DLC coated samples using multi-directional method, varying the upper and lower cut-off limits

The power spectra show differences between the two surface-type topographies. The fractal characterisation shows that the DLC surfaces have a lower characteristic surface wavelength (higher roll-off frequency) than the Steel ones.

Persson et al [49] defined the system length scale as: $\lambda=L / \gamma$, where $L$ is twice the Hertzian contact semi-half width (i.e. the contact width) and $\gamma$ is the magnification factor of the measuring instrument for the appropriate lateral resolution. If $\omega_{L}=2 \pi / L$ and $\omega=\omega_{L} \gamma$, then the length scale of the contact can be defined as:

$$
\lambda=\frac{2 \pi}{\omega_{L} \gamma}
$$

where, the Hertzian contact width can be calculated as: 
$L=2\left(\frac{3 F_{N} R}{4 E^{*}}\right)^{\frac{1}{3}}$

Then, the system would have a wavelength cut-off defined by: $\omega_{0}=2 \pi / \lambda_{0}$. Given that self-affine fractal surfaces should comply with the condition: $\omega \gg \omega_{0}$ (as displayed by the Steel surface in the current paper), it can be shown that [49]:

$G(\gamma)=\left(\frac{\omega_{0} \sigma}{4\left(1-v^{2}\right)}\right)^{2} \frac{\alpha H}{(1-H)}\left(\frac{E}{\sigma_{0}}\right)^{2}\left(\frac{\omega}{\omega_{0}}\right)^{2(1-H)}$

If the surface topography displays a roll-off limit such that $\omega<\omega_{0}$ as displayed by the DLC surface measurements shown in Figure 10 and $E$ as described in equation (3), then the surface created through a growth process commonly displays roll-off frequencies which are a function of the deposition time. For this case it can be shown that [49]:

$G(\gamma)=\frac{\alpha H}{8}\left(\frac{E}{\left(1-v^{2}\right) \sigma_{0}}\right)^{2}\left(\frac{\sigma}{q_{0}}\right)^{2} \omega_{0}^{4}\left\{\frac{1}{4}\left[1-\left(\frac{\omega_{L}}{\omega_{0}}\right)^{4}\right]+\frac{1}{2(1-H)}\left[\left(\frac{\omega}{\omega_{0}}\right)^{2(1-H)}-1\right]\right\}$

where:

$\alpha=\left[1+H-\left(\frac{\omega_{L}}{\omega_{0}}\right)^{2} H\right]^{-1}$

The Hurst exponent is: $H=2-D$, when the fractal dimension $D$ falls within the interval: $(1<D>$ 2). If a surface shows linear self-affine behaviour for the contact nominal diameter, $L$, then the value for $\omega_{0}=\omega_{L}=2 \pi / L$. As the mean contact stress is given by: $\sigma_{0}=F_{N} / A_{0}$, the asperity contact area as a function of length scale can be written as [49]:

$$
A(\lambda)=A_{0}[\pi G(\gamma)]^{-\frac{1}{2}}
$$

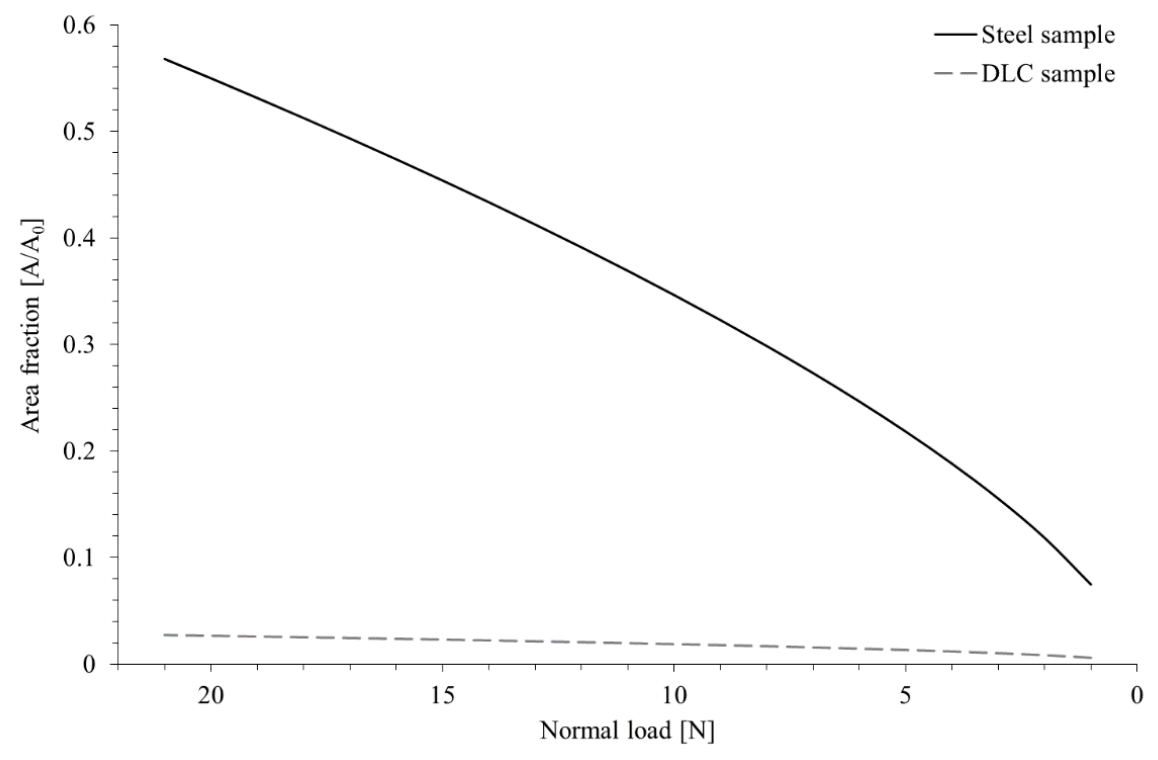

Figure 11: Predicted asperity contact area as a function of applied load

Figure 11 shows the variation of the predicted asperity contact area with applied load. The result precludes any load carrying capacity due to piezo-viscous lubricant action (elastohydrodynamics), which is likely to occur in practice. Therefore, the results do not directly describe the real contact areas under a particular applied load by the test rig. However, the results serve to explain a contributing mechanism through which mixed and boundary friction is reduced when using PECVD DLC coated surfaces. 
Referring back to Figure 8, it is shown that the increased rate of lubricant entrainment reduces the total friction as the direct interaction of surface asperities carry a progressively smaller proportion of the applied force $(20 \mathrm{~N})$. Figure 11 shows that the surface topography of the DLC-coated sample produces the same load carrying capacity as that of a Steel contacting pair, but at a significantly reduced real contact area. Considering engineering applications are commonly lubricated and therefore form a tribofilm within the contact, then the generated friction, $f$, in mixed elastohydrodynamic regime of lubrication is as the result of combined boundary and viscous friction, as:

$f=f_{v}+f_{b}$

where:

$f_{b}=\tau_{b} A(\lambda)$

where, $\tau_{b}$ represents the boundary shear strength of the surface tribofilm formed within the contact. This is defined as [52]:

$\tau_{b}=\tau_{0}+\zeta \bar{p}$

where, $\zeta$ is defined as the pressure coefficient of boundary shear strength of the surface, $\bar{p}$ is the mean pressure at the asperity contact and $\tau_{0}$ is the Erying shear stress of the lubricant. As the contact pressure is limited by the plastic yield of the surface, then the boundary friction becomes largely dependent on the asperity contact area, which can be determined as shown here and $\zeta$ which can be measured using AFM in lateral force mode (LFM) [15]. Therefore, the nanoscale asperity area and surface composition along with topography have significant effects on the boundary friction within the contact of the investigated DLC coating.

This approach uses analytical expressions and surface-specific topographical parameters, determined experimentally, which enable prediction of the complex lubricant-surface systems fractal nanoscale asperity contact area. The use of the scale-independent fractal model for the characterisation of the rough surfaces allows a surface-specific lower wavelength (roll off) cut-off in order to describe contributing mechanisms for improved boundary friction.

\section{Concluding remarks}

The paper demonstrates the frictional improvement with DLC-on-DLC coated tribo-pairs, using a fully instrumented and controlled precision pin-on-disc tribometer. The replicated conditions represent those of high performance racing transmission involute spur gear pairs. These are under high loads, shear and contact temperatures with non-Newtonian tractive mixed elastohydrodynamic regime of lubrication. Reported literature is limited for testing at such severe conditions. Comparisons are made with superfinished Steel-on-Steel tribo-pairs using a fully formulated high performance transmission fluid. The hydrogenated DLC-on-DLC tribo-pairs show improved frictional performance in comparison to the Steel-on-Steel counterparts. The paper shows multiscale measurement of surfaces of tested samples using white light interferometry as well as atomic force microscopy to demonstrate the self-affine nature of the samples, thus their conformance to multiscale fractal representation. The surface microscopy highlighted the need for high resolution (lateral and vertical) measurements to allow suitable characterisation of the DLC topography.

A multiscale fractal-based analytical contact mechanics model is employed which shows that reduced real asperity contact area of the investigated DLC-on-DLC tribo-pair explains the underlying mechanism for improved friction, whilst attaining the same load carrying capacity as that of the steelon-steel counterpart within this highly loaded mixed regime of lubricated contact. This reduced area of contact in combination with the formation of a tribo-film from the fully formulated lubricant explains the improved frictional performance. This is the main finding and contribution to knowledge of the paper. 


\section{Acknowledgements}

The authors would like to express their gratitude to the Engineering and Physical Science Research Council (EPSRC) for the financial support extended to this research through the Doctoral Training Program (DTP). The authors also acknowledge the use of facilities within the Loughborough Materials Characterisation Centre (LMCC).

\section{References}

[1] J. King, The king review of low-carbon cars Part 1: the potential for CO2 reduction. London: Office of Public Sector Information, Hm Treasury, HMSO, 2007.

[2] H. Rahnejat, Multi-body Dynamics: Vehicles, Machines and Mechanisms, Professional Engineering Publishing, Bury St Edmunds, UK, 1998.

[3] C. P. O. Treutler, "Industrial use of plasma-deposited coatings for components of automotive fuel injection systems", Surf. Coatings Technol., 2005, 200(5-6), pp. 1969-1975.

[4] A. Matthews and S. Eskildsen, "Engineering applications for diamond-like carbon", Diam. Relat. Mater., 1994, 3, pp. 902-911.

[5] J. Robertson, "Diamond-like amorphous carbon", Mater. Sci. Eng. Reports, 2002, 37, pp. 129281.

[6] A. Erdemir and C. Donnet, "Tribology of diamond-like carbon films: Recent progress and future prospects”, J. Phys., D: Appl. Phys., 2006, 39(18): R311.

[7] M. Teodorescu, H. Rahnejat, R. Gohar and D. Dowson, "Harmonic decomposition analysis of contact mechanics of bonded layered elastic solids", Appl. Math. Modelling, 2009, 33(1), pp. 467-485.

[8] K. Topolovec-Miklozic, F. Lockwood, and H. Spikes, "Behaviour of boundary lubricating additives on DLC coatings", Wear, 2008, 265(11-12), pp. 1893-1901.

[9] R. Gohar and H. Rahnejat, Fundamentals of Tribology, Second ed., London: Imperial Collage Press, 2012.

[10] K. Holmberg, A. Matthews, and H. Ronkainen, "Coatings tribology — contact mechanisms and surface design”, Tribol. Int., 1998, 31(1), pp. 107-120.

[11] J. Robertson, "Diamond-like carbon”, Pure Appl. Chem., 1994, 66(9), pp. 1789-1796.

[12] H. Ronkainen, S. Varjus, J. Koskinen, and K. Holmberg, "Differentiating the tribological performance of hydrogenated and hydrogen-free DLC coatings", Wear, 2001, 249(3-4), pp. 260-266.

[13] M. Kalin, I. Velkavrh, J. Vizintin, and L. Ozbolt, "Review of boundary lubrication mechanisms of DLC coatings used in mechanical applications", Meccanica, 2008, 43(6), pp. 623-637.

[14] A. Erdemir, "Review of engineered tribological interfaces for improved boundary lubrication", Trib. Int., 2005, 38(3), pp. 249-256.

[15] M. Leighton, T. Nicholls, M. De la Cruz, R. Rahmani and H. Rahnejat, "Combined lubricantsurface system perspective: Multi-scale numerical-experimental investigation", Proc. IMechE, Part J: J. Engineering Trib., 2017, 231(7), pp. 910-924.

[16] S. Neuville and A. Matthews, "A perspective on the optimisation of hard carbon and related coatings for engineering applications," Thin Solid Films, vol. 515, no. 17, pp. 6619-6653, 2007.

[17] M. De Feo, M.D. Bouchet, C. Minfray, T. Le Mogne, F. Meunier, L. Yang, B. Thiebaut, and J.M. Martin JM, "MoDTC lubrication of DLC-involving contacts. Impact of MoDTC degradation", Wear, 2016, 348, pp. 116-125.

[18] T. Haque, A. Morina, A. Neville, R. Kapadia, and S. Arrowsmith, "Effect of oil additives on the durability of hydrogenated DLC coating under boundary lubrication conditions," Wear, vol. 
266, no. 1-2, pp. 147-157, 2009.

[19] M. De Feo, M.D. Bouchet, C. Minfray, C. Esnouf, T. Le Mogne, F. Meunier, L. Yang, B. Thiebaut, S. Pavan and J.M. Martin, "Formation of interfacial molybdenum carbide for DLC lubricated by MoDTC: Origin of wear mechanism", Wear, 2017, 370, pp. 17-28.

[20] S. Kosarieh, A. Morina, E. Lainé, J. Flemming, and A. Neville, "The effect of MoDTC-type friction modifier on the wear performance of a hydrogenated DLC coating", Wear, 302(1-2), pp. 890-898.

[21] M.D. Bouchet, C. Matta, B. Vacher, T. Le-Mogne, J.M. Martin, J. von Lautz, T. Ma, L. Pastewka, J. Otschik, P. Gumbsch and M. Moseler, "Energy filtering transmission electron microscopy and atomistic simulations of tribo-induced hybridization change of nanocrystalline diamond coating", Carbon, 2015, 87, pp. 317-329.

[22] B. Vengudusamy, J. H. Green, G. D. Lamb, and H. A. Spikes, "Behaviour of MoDTC in DLC/DLC and DLC/steel contacts", Tribol. Int., 2012, 54, pp. 68-76.

[23] B. Podgornik, D. Hren, J. Vižintin, S. Jacobson, N. Stavlid, and S. Hogmark, "Combination of DLC coatings and EP additives for improved tribological behaviour of boundary lubricated surfaces", Wear, 2006, 261(1), pp. 32-40.

[24] M. Kalin and I. Velkavrh, "Non-conventional inverse-Stribeck-curve behaviour and other characteristics of DLC coatings in all lubrication regimes", Wear, 2013, 297(1-2), pp. 911-918.

[25] M. I. De Barros'Bouchet, J. M. Martin, T. Le-Mogne, and B. Vacher, "Boundary lubrication mechanisms of carbon coatings by MoDTC and ZDDP additives," Tribol. Int., vol. 38, no. 3, pp. 257-264, 2005.

[26] C. A. Manier, H. Ziegele, J. Barriga, J. Goikoetxea, and M. Woydt, "Zirconium-based coatings in highly stressed rolling contacts as alternative solution to DLC and ta-C coatings," Wear, vol. 269, no. 11-12, pp. 770-781, 2010.

[27] M. Kano, "Super low friction of DLC applied to engine cam follower lubricated with estercontaining oil", Tribol. Int., 2006, 39(12), pp. 1682-1685.

[28] H.A. Tasdemir, M. Wakayama, T. Tokoroyama, H. Kousaka, N. Umehara, Y. Mabuchi and T. Higuchi, "Ultra-low friction of tetrahedral amorphous diamond-like carbon (ta-C DLC) under boundary lubrication in poly alpha-olefin (PAO) with additives", Trib. Int., 2013, 65, pp. 286294.

[29] E. Humphrey, N. Morris, M. Leighton, R. Rahmani and H. Rahnejat, "Multiscale Friction in Lubricant-Surface Systems for High-Performance Transmissions Under Mild Wear", Trib. Letters, 2018, 66(3), p. 77.

[30] V. Elisaus, M. Mohammadpour, S. Theodossiades and H. Rahnejat, "Effect of teeth microgeometrical form modification on contact kinematics and efficiency of high performance transmissions", Proc. IMechE, Part K: J. Multi-body Dynamics, 2017, 231(3), pp. 538-555.

[31] E. Fatourehchi, V. Elisaus, M. Mohammadpour, S. Theodossiades, and H. Rahnejat, "Efficiency and Durability Predictions of High Performance Racing Transmissions," SAE Int. J. Passeng. Cars - Mech. Syst., 2016, 9(3), Pap. No. 2016-01-1852.

[32] J. A. Greenwood, "Film thicknesses in circular elastohydrodynamic contacts", Proc. IMechE, Part C: J. Mech. Eng. Sci., 1988, 202(1), pp. 11-17.

[33] M. Reiner, “The Deborah Number", Phys. Today, 1964, 17(1), p. 62.

[34] A. Neville, A. Morina, T. Haque, and M. Voong, "Compatibility between tribological surfaces and lubricant additives-How friction and wear reduction can be controlled by surface/lube synergies," Tribol. Int., vol. 40, no. 10-12 SPEC. ISS., pp. 1680-1695, 2007.

[35] T. Y. Leung, W. F. Man, P. K. Lim, W. C. Chan, F. Gaspari, and S. Zukotynski, "Determination of the sp3/sp2 ratio of a-C:H by XPS and XAES," J. Non. Cryst. Solids, vol. 254, no. 1-3, pp. 
156-160, 1999.

[36] R.J. Chittenden, D. Dowson, J.F. Dunn and C.M. Taylor, "A theoretical analysis of the isothermal elastohydrodynamic lubrication of concentrated contacts. I. Direction of lubricant entrainment coincident with the major axis of the Hertzian contact ellipse", Proc. Roy. Soc. Lond. A., 1985, 397(1813), pp. 245-269.

[37] S. J. Cho, K. R. Lee, K. Yong Eun, J. Hee Hahn, and D. H. Ko, "Determination of elastic modulus and Poisson's ratio of diamond-like carbon films," Thin Solid Films, vol. 341, no. 1, pp. 207-210, 1999.

[38] A. Majumdar and B. Bhushan, "Role of fractal geometry in roughness charaterisation and contact mechanics of surfaces", Trans. ASME, J. Trib., 1990, 112, pp. 205-216.

[39] S. Ganti and B. Bhushan, "Generalized fractal analysis and its applications to engineering surfaces”, Wear, 1995, 180(1-2), pp. 17-34.

[40] K. L. Johnson, Contact Mechanics, Cambridge University Press, Cambridge, UK, 1985.

[41] A. Majumdar and B. Bhushan, "Fractal model of elastic-plastic contact between rough surfaces", Trans. ASME, J. Trib., 1991, 113(1), pp. 1-11.

[42] L. Kogut and I. Etsion, "Elastic-plastic contact analysis of a sphere and a rigid flat", J. Appl. Mech., 2002, 69(5), pp. 657-662.

[43] L. Kogut and I. Etsion, "Adhesion in elastic-plastic spherical microcontact", J. Colloid and Interface Sci., 2003, 261(2), pp. 372-378.

[44] W.W.F. Chong, M. Teodorescu and H. Rahnejat, "Nanoscale elastoplastic adhesion of wet asperities", Proc. IMechE, Part J: J. Engineering Trib., 2013, 227(9), pp.996-1010.

[45] A. Majumdar and C. L. Tien, "Fractal characterization and simulation of rough surfaces," Wear, 1990, 136(2), pp. 313-327.

[46] M. Leighton, N. Morris, M. Gore, R. Rahmani, H. Rahnejat and P.D. King, "Boundary interactions of rough non-Gaussian surfaces". Proc. IMechE, Part J: J. Engineering Trib., 2016 230(11), pp. 1359-1370.

[47] B. N. J. Persson, "On the Fractal Dimension of Rough Surfaces", Trib. Lett., 2014, 54(1), pp. 99-106.

[48] B. N. J. Persson and E. Tosatti, "The effect of surface roughness on the adhesion of elastic solids", J. Chemical Phys., 2001, 115(12), pp. 5597-5610.

[49] B. N. J. Persson, "Elastoplastic contact between randomly rough surfaces", Phys. Rev. Lett., 87(11), 2001, p 116101.

[50] B. N. J. Persson, O. Albohr, U. Tartaglino, A. I. Volokitin and E. Tosatti, "On the nature of surface roughness with application to contact mechanics, sealing, rubber friction and adhesion", J. Phys. Condens. Matter, 2004, 17(1): R1.

[51] A. Majumdar and B. Bhushan, "Role of Fractal Geometry in Roughness Characterization and Contact Mechanics of Surfaces", Trans. ASME, J. Trib., 1990, 112(2), pp. 205-216.

[52] B. J. Briscoe and D. C. B. Evans, "The shear properties of Langmuir - Blodgett layers", Proc. Roy. Soc. A: Math. Phys. Eng. Sci., 1982, 380, pp. 389-407. 